Р.Г. Сидоренко, О.М. Порохончук

Харківський національний університет Повітряних Сил ім. І. Кожедуба, Харків

\title{
ОЦІНКА ЕФЕКТИВНОСТІ ЗАСОБІВ ЗНИЖЕННЯ ПОМІТНОСТІ ОБ'ЄКТІВ У ІНФРАЧЕРВОНОМУ ДІАПАЗОНІ ДОВЖИН ХВИЛЬ
}

Проведено очінку можливостей апаратури інфрачервоної (тепловізійної) розвідки, яка встановлена на літальних апаратах та наземних засобах щчодо виявлення об'єктів. Наведені необхідні для розрахунків вихідні дані по апаратурі, об’єктам та умовам ведення розвідки. Отримано аналітичні вирази для розрахунку відношення сигналу до шуму зображень вихідного й замаскованого об'єктів та ймовірностей їх виявлення. Розроблено математичний апарат для оиінки ефективності заходів зниження помітності у інфрачервоному діапазоні довжин хвиль. Отримані результати можуть використовуватись при розробиі нових засобів зниження помітності в інфрачервоному діапазоні довжин хвиль та оціниі ефективності існуючих й перспективних засобів зниження помітності від апаратури тепловізійної розвідки.

Ключові слова: апаратура тепловізійної розвідки, засоби зниження помітності, оцінка ефективності, ймовірність виявлення об'єкта.

\section{Вступ}

В теперішній час в збройних силах провідних країн світу для виявлення і розпізнавання наземних, повітряних та морських об'єктів, а також забезпечення нанесення ударів в нічних та складних метеоумовах широко використовується інфрачервона (IЧ) розвідка. Під інфрачервоною розвідкою розуміється отримання інформації шляхом прийому i аналізу електромагнітних сигналів ІЧ діапазону хвиль, що випромінювали об'єктами і предметами навколишньої місцевості або відображених. ІЧ розвідка підрозділяється на видову і параметричну. Видова IЧ розвідка забезпечує отримання інформації у вигляді зображень різних об'єктів і місцевості, а параметрична ІЧ розвідка забезпечує здобування інформації, що міститься в просторових і випромінювальних характеристиках різних об'єктів та місцевості. Аналізуючи відбите об'єктами ІЧ випромінювання Сонця, Місяця, зоряного неба, можна зробити висновок, що діапазон цього випромінювання припадає на ділянку спектра до 3 мкм. Часто цю довжину хвилі вважають граничною, що розділяє відображену i власну складові ІЧ випромінювання об'єктів. Тому можна вважати, що в ближній частині ІЧ спектру (до 3 мкм) визначальною при веденні розвідки є відбивна складова, і розподіл проміневості по об'єктах залежить від розподілу коефіцієнтів відбиття i опромінення. Для ІЧ частини спектра більше 3 мкм визначальним $є$ власне випромінювання об'єктів, а розподіл проміневості залежить від розподілу коефіцієнтів випромінювання і температури.

Відповідно до цього сучасні засоби розвідки працюють або на принципі прийому відбитого об'єктами випромінювання спеціальних випромінювачів, Місяця, зоряного неба (прилади нічного бачен- ня, ПНБ), або прийому власного випромінювання об'єктів (тепловізори, теплопеленгатори, радіометри).

У військовій сфері найбільше застосування знаходять тепловізори, що призначені для одержання візуального зображення земної поверхні і наземних об'єктів, які мають різну температуру або відбивну здатність. Тепловізійна розвідка може проводитися в будь-який час доби, але вона більш ефективна вночі, коли наземні об'єкти не відображають сонячного світла. Як фотоприймачі в засобах тепловізійної розвідки використовуються переважно фотоопір, тобто пристрій, який при впливі на нього променевої енергї̈ змінює свій електричний опір. Зміни опору перетворюються далі в зміни електричного струму, які відповідають тепловому зображенню об'єкта.

Залежно від типу застосовуваних фотоприймачів довгохвильова границя чутливості засобів тепловізійної розвідки становить до 3-8 мкм при використанні фотоопору з сірчистого або селениста свинцю і селеніду індію або до 12 мкм.

Постановка проблеми. Все вище зазначене говорить про необхідність значно підвищити увагу до розробки та застосування новітніх засобів маскування в ІЧ діапазоні хвиль, а також оцінки їх можливості щодо зниження помітності важливих військових об'єктів й озброєння та військової техніки (OBТ) від сучасних та перспективних засобів ІЧ розвідки.

Тому, з огляду на важливість вирішення проблеми захисту об'єктів ОВТ від засобів ІЧ розвідки та застосування засобів зниження помітності для забезпечення необхідної ІЧ помітності об'єктів повинно мати відповідне наукове обгрунтування і спиратися на прогноз очікуваних результатів, що обумовлює необхідність проведення подальших досліджень, спрямованих, насамперед, на розвиток теорії 
і практики оцінки застосування засобів маскування i розробку практичних рекомендацій щодо захисту об'єктів ОВТ від зазначеної апаратури.

Аналіз останніх досліджень і публікацій. Питанням зниження помітності об'єктів у ІЧ довжин хвиль за рахунок використання засобів маскування в останній час приділяється багато уваги. В роботах [1-8] розглянуті основні напрямки створення зазначених засобів, а також методи зниження ефективності застосування систем виявлення об'єктів у ІЧ діапазоні довжин хвиль. Однак оцінок ефективності застосування засобів зниження помітності для захисту об'єктів в реальній обстановці не проведено та не розроблений математичний апарат для цих цілей.

Мета статті - розробка методики оцінки ефективності застосування засобів зниження помітності від апаратури тепловізійної розвідки.

\section{Виклад основного матеріалу}

Проведемо оцінку можливостей розвідки об’єктів системами тепловізійної розвідки, які встановлені на літаках-розвідниках, БпЛА та наземних засобах в діапазонах довжин хвиль 3,2-5,2 мкм, 8-14 мкм.

Для оцінки можливостей тепловізійної розвідки будемо використовувати такий показник, як імовірність виявлення об'єкта $-P_{o}$.

Для визначення наведеного показника необхідні наступні вихідні дані:

- по апаратурі розвідки:

1) гранична чутливість за температурою $\Delta T_{0}$ $K$; 2) елементарний кут зору $\delta_{e}$, рад; 3 ) дальність ведення розвідки $\left.D_{H}, \mathrm{M} ; 4\right)$ кут візування $\psi_{B}$;

- по об'єкту розвідки:

1) коефіцієнт теплового випромінювання покриття об'єкту $\left.\varepsilon_{0} ; 2\right)$ коефіцієнт теплового випромінювання фону $\varepsilon_{\phi}$; 3) коефіцієнт теплового випромінювання покриття замаскованого об'єкту $\varepsilon_{3}$; 4) площа проекції об'єкта на площину, перпендикулярну до лінії візування апаратурою розвідки $\left.S_{0}, \mathrm{м}^{2} ; 5\right)$ площа проекції елементу випромінюючої поверхні об'єкту, перпендикулярну до лінії візування апаратурою розвідки $S_{0 i}, \mathrm{~m}^{2}$;

- по умовам ведення розвідки:

1) коефіцієнт пропускання атмосфери $\tau$; 2) середня температура об'єкту $\left.t_{0} ; 3\right)$ середня температура фону $t_{\phi}$.

Розрахунок імовірності виявлення об'єкту здійснюється в наступній послідовності.

Визначаються вихідні дані: за апаратурою розвідки $\left(\Delta T_{0}, \delta_{\beta}, D_{H}\right)$; по об'єкту $\left(\varepsilon_{0}, \varepsilon_{\phi}\right)$ за табл. 1 ; за умовами ведення розвідки $(\tau)$ за рис. 1-2 [9-10].
Таблиця 1

Коефіцієнти теплового випромінювання $\left(\varepsilon_{0}, \varepsilon_{\phi}\right)$

матеріалів та підстилаючих поверхонь (фонів)

\begin{tabular}{|c|c|}
\hline Матеріал поверхні (фон) & $\begin{array}{c}\text { Коефіцієнти теплового } \\
\text { випромінювання }\end{array}$ \\
\hline Алюміній & $0,06-0,07$ \\
\hline Залізо & $0,24-0,28$ \\
\hline Сталь & 0,56 \\
\hline Чавун & 0,95 \\
\hline Листя зелене & $0,95-0,98$ \\
\hline Сніг & $0,8-0,85$ \\
\hline Пісок & 0,6 \\
\hline Асфальт & 0,95 \\
\hline Гравій & 0,94 \\
\hline
\end{tabular}

Джерело: Розроблено авторами за даними [9-10].

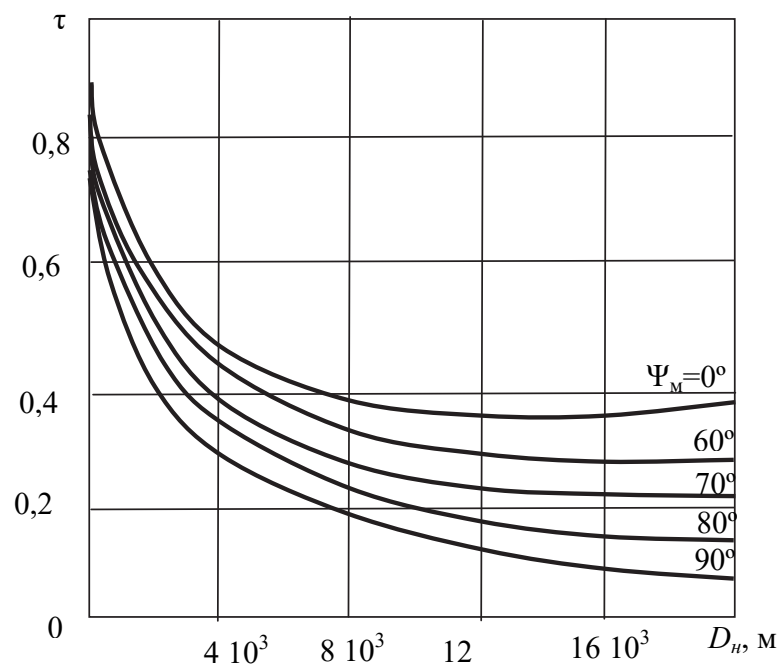

Рис. 1. Залежність коефіцієнта пропускання атмосфери $\tau$ в спектральному діапазоні 3,2-5,2 мкм від дальності $D_{H}$ для різних кутів візування $\psi_{M}$ Джерело: Розроблено авторами за даними [9-10].

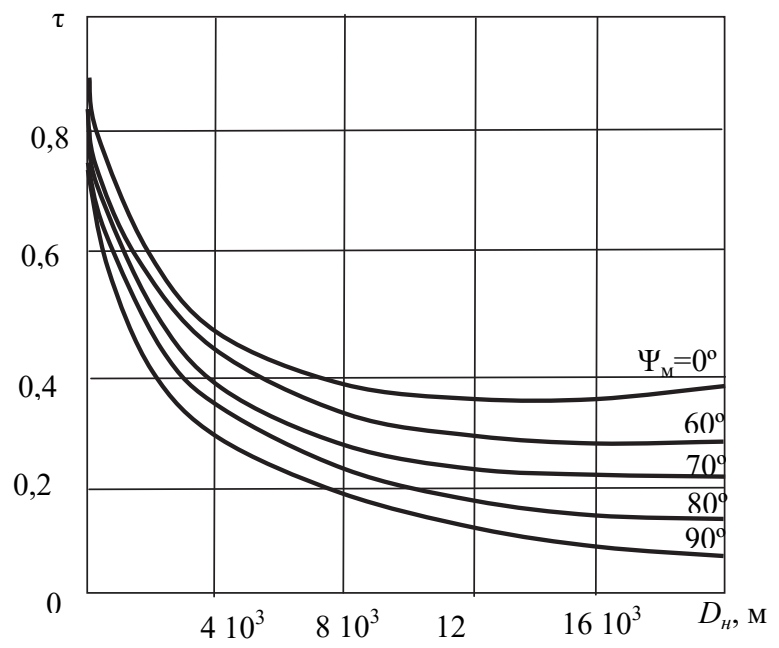

Рис. 2. Залежність коефіцієнта пропускання атмосфери $\tau$ в спектральному діапазоні 8-14 мкм від дальності $D_{H}$ для різних кутів візування $\psi_{M}$ Джерело: Розроблено авторами за даними [9-10]. 
За допомогою термометрів (табл. 2) [11] відповідно до інструкції їх використання вимірюються температури $t_{\phi i}$ в декількох точках навколо об'єкту та температури $t_{o i}$ окремих, що відрізняються за нагрівом характерних ділянок (елементів) об'єкту $S_{o i}$, після чого розраховуються середнє значення температур фону $t_{\phi}$ і об'єкту $t_{0}$ за формулами:

$$
\begin{aligned}
& t_{\phi}=\sqrt[4]{\frac{1}{m} \sum_{i=1}^{m} t_{\phi i}^{4}} \\
& t_{o}=\sqrt[4]{\frac{1}{S_{o}} \sum_{i=1}^{m} t_{o i}^{4}} S_{o i},
\end{aligned}
$$

де $m$ - кількість вимірів.

Розраховуються величини:

- елемент розкладання $\Delta l_{m}$, м за виразом:

$$
\Delta l_{m}=D_{H} \delta_{e}
$$

- еквівалентна похибка об'єкту $b_{e}$, м за вира30M:

$$
b_{e}=\frac{S_{o}}{l_{m o}}
$$

- коефіцієнт, що враховує здатність зорового аналізатора оператора-дешифрувальника здійснювати просторове інтегрування по полю теплового зображення об'єкту $N$, за виразом:

$$
N=\left\{\begin{array}{l}
\frac{0,8 b_{e} l_{m o}}{l_{m}^{2}} \text { nрu } \frac{b_{e}}{\Delta l_{m}}<1, \frac{l_{m o}}{\Delta l_{m}}<1 \\
\frac{\sqrt{\frac{l_{m o}}{\Delta l_{m} b_{e}}}}{\Delta l_{m}} \text { npu } \frac{b_{e}}{\Delta l_{m}}<1,1 \leq \frac{l_{m o}}{\Delta l_{m}} \leq 13 ; \\
\frac{\sqrt{b_{e} l_{m o}}}{\Delta l_{m}} \text { nрu } 1 \leq \frac{b_{e}}{\Delta l_{m}} \leq 13,1 \leq \frac{l_{m o}}{\Delta l_{m}} \leq 13 ; \\
\frac{\sqrt{13 b_{e}}}{\Delta l_{m}} \text { nрu } \frac{b_{e}}{\Delta l_{m}}<1, \frac{l_{m o}}{\Delta l_{m}}>13 \\
\frac{\sqrt{13 b_{e}}}{\Delta l_{m}} \text { nрu } 1 \leq \frac{b_{e}}{\Delta l_{m}} \leq 13, \frac{l_{m o}}{\Delta l_{m}}>13 \\
\sqrt{170} \text { nрu } \frac{b_{e}}{\Delta l_{m}}>13, \frac{l_{m o}}{\Delta l_{m}}>13 .
\end{array}\right.
$$

Далі розраховується величина відношення сигналу до шуму $q$, за виразом:

$$
q=\frac{\left(\left|\varepsilon_{\phi}\left(t_{o}-t_{\phi}\right)+\eta\left(\varepsilon_{o}-\varepsilon_{\phi}\right)\right|\right) N \tau}{\Delta T_{0}}-3,2,
$$

де $\eta$ - коефіцієнт, що враховує вплив випроміню-

\begin{tabular}{|c|c|c|c|}
\hline Прилад & Призначення & $\begin{array}{l}\text { Границі } \\
\text { вимірю- } \\
\text { вань, }{ }^{\circ} \mathrm{C}\end{array}$ & $\begin{array}{c}\text { Похиб- } \\
\text { ка ви- } \\
\text { мірю- } \\
\text { вань }\end{array}$ \\
\hline $\begin{array}{c}\text { Термометр } \\
\text { опору } \\
\text { ТСП-309 }\end{array}$ & $\begin{array}{c}\text { Вимір різних } \\
\text { температурних } \\
\text { поверхонь }\end{array}$ & $0-120$ & $2 \%$ \\
\hline $\begin{array}{c}\text { Термометр } \\
\text { термоелек- } \\
\text { тричний } \\
\text { TXА-1479 }\end{array}$ & $\begin{array}{c}\text { Вимір різних } \\
\text { температурних } \\
\text { поверхонь }\end{array}$ & $\begin{array}{l}0-400 \\
0-750\end{array}$ & $1^{\circ} \mathrm{C}$ \\
\hline $\begin{array}{c}\text { Термометр } \\
\text { термоелек- } \\
\text { тричний } \\
\text { КК-0665 } \\
\end{array}$ & $\begin{array}{c}\text { Вимір } \\
\text { температури } \\
\text { води }\end{array}$ & $0-350$ & $0,5^{\circ} \mathrm{C}$ \\
\hline $\begin{array}{c}\text { Термометр } \\
\text { TM-3 }\end{array}$ & $\begin{array}{c}\text { Вимір } \\
\text { температури } \\
\text { поверхні грунту }\end{array}$ & $\begin{array}{c}-35-+60 \\
-25-+760 \\
-10-+85\end{array}$ & $0,5^{\circ} \mathrm{C}$ \\
\hline $\begin{array}{c}\text { Термометр } \\
\text { TM-10 }\end{array}$ & $\begin{array}{c}\text { Вимір } \\
\text { температури } \\
\text { різних глибин- } \\
\text { них шарів грунту } \\
\text { та поверхонь } \\
\text { шару води } \\
\text { у водоймищах }\end{array}$ & $\begin{array}{c}\text { Для } \\
\text { грунту: } \\
-20-+30 \\
-10-+40 \\
\text { для води: } \\
-5-+40\end{array}$ & $0,2^{\circ} \mathrm{C}$ \\
\hline
\end{tabular}
вання атмосфери;

$$
\eta=\left\{\begin{array}{l}
35 \text { при ясній погоді; } \\
25 \text { при високій хмарності; } \\
15 \text { при низькій хмарності. }
\end{array}\right.
$$

Таблиця 2

Прилади для вимірювання температур фонів та об'єктів

Джерело: Розроблено авторами за даними [11].

Імовірність виявлення об'єкту $P_{o}$ визначається згідно графіка, зображеного на рис. 3 [12].

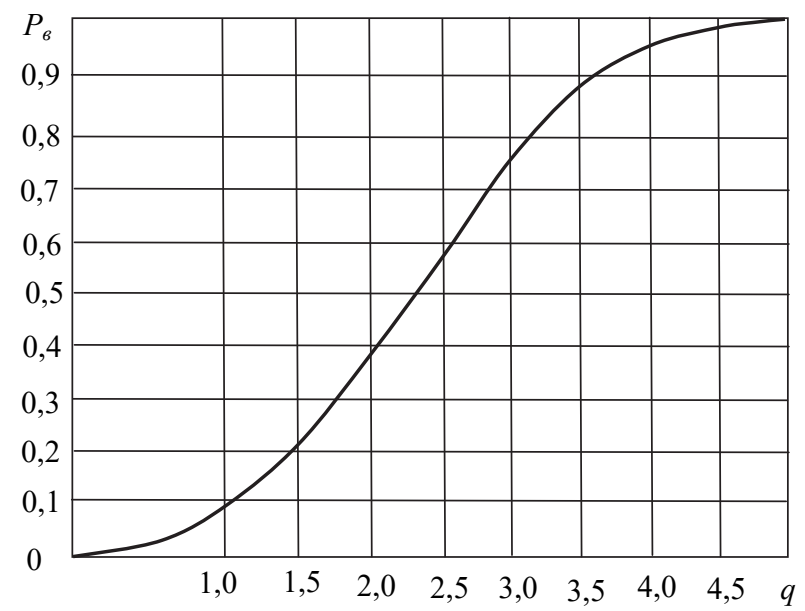

Рис. 3. Залежність імовірності виявлення об'єкта $P_{o}$ від співвідношення сигнал/шум $q$

Джерело: Розроблено авторами за даними [12].

Тепер розраховується величина відношення сигналу до шуму замаскованого об'єкту $q_{3}$, за виразом:

$$
q=\frac{\left(\left|\varepsilon_{\phi}\left(t_{30}-t_{\phi}\right)+\eta\left(\varepsilon_{30}-\varepsilon_{\phi}\right)\right|\right) N \tau}{\Delta T_{0}}-3,2 .
$$


Імовірність виявлення замаскованого об'єкту

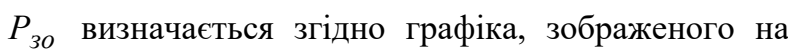
рис. 2.

Ефективність застосування засобів зниження помітності від апаратури тепловізійної розвідки оцінюється за формулою:

$$
E_{3 n}=\left(P_{o}-P_{30}\right) \cdot 100 \% \text {. }
$$

\section{Висновки}

Таким чином, розроблено методику оцінки ефективності заходів маскування об'єктів від апаратури тепловізійної розвідки.

Крім того, в ході досліджень отримані аналітичні вирази для розрахунку відношення сигналу до шуму зображень вихідного й замаскованого об'єктів та ймовірностей виявлення вихідного й замаскованого об'єкту.

Отримані результати можуть забезпечити розрахункову оцінку можливостей апаратури тепловізійної розвідки конкретних об'єктів захисту в заданих умовах, необхідну для виявлення особливо небезпечних засобів виявлення та ураження противника, визначення демаскуючих ознак, вибору та розробки способів та засобів протидії й оцінки їх ефективності. Також вони можуть використовуватись при розробці нових засобів зниження помітності в інфрачервоному діапазоні довжин хвиль та оцінці ефективності існуючих й перспективних засобів зниження помітності від апаратури тепловізійної розвідки.

\section{Список літератури}

1. Сидоренко Р. Г., Акулінін Г. В., Скопінцев О. О. Пасивні засоби радіоелектронного захисту об'єктів від впливу сучасних та перспективних засобів ураження. Наука і техніка Повітряних Сил Збройних Сил України. 2017. № 1(26). C. 156-159. https://doi.org/10.30748/nitps.2017.26.31.

2. Сидоренко Р. Г., Мегельбей Г. В., Рибалка Г. В., Резніченко А. І., Скопінцев О. О. Шляхи удосконалення радіоелектронного захисту об'єктів від впливу сучасних та перспективних засобів виявлення та ураження. Збірник наукових

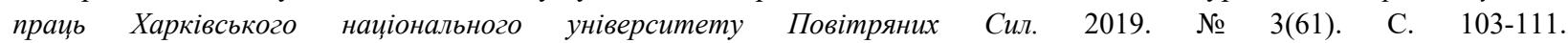
https://doi.org/10.30748/zhups.2019.61.13.

3. Умение быть невидимым. Конструкция “Контраст КМС” - квинтэссенция маскировочного искусства. Defense Express. 2004. № 12(37).

4. Савенков А. Разработка высокоточных всепогодных систем наведения малоразмерных средств поражения объектов ВВТ. Оборонная техника. 1990. № 9. С. 18-19.

5. Королев А. Ю., Королева А. А., Яковлев А. Д. Маскировка вооружения, техники и объектов. Санкт-Петербург : университет ИМТО, 2015. 154 с.

6. Гурский Б., Свободин А. Системы наведения ракет класса “земля-земля” - основа дальнего огневого поражения наземных целей. Высокоточное оружсие. 2003. С. 24-26.

7. Воробьев И. Н. Тактика - искусство боя. Москва : ОА ВС РФ, 2002. 862 с.

8. Рольф Хилмес. Боевые машины и тепловое изображение. URL: http://armor.kiev.ua/ ptur/demask/RolfHilmes (дата звернення: 02.06.2021).

9. Сидоренко Р. Г., Акулінін Г. В., Безверхий С. А., Сафарова Г. М. Методика оцінки ефективності заходів маскування у видимому діапазоні довжин хвиль. Системи озброєння $і$ військова техніка. 2020. № 3(63). С. 31-37. https://doi.org/10.30748/soivt.2020.63.05.

10. Стаховський О. В. Вирішення танковими (механізованими) підрозділами задачі маскування. Системи озброєння і військова техніка. 2010. № 1(21). С. 87-90.

11. Сидоренко Р. Г., Акулінін Г. В., Безверхий С. А., Гончаров А. А. Ефективність заходів радіоелектронного захисту об'єктів від радіометричних систем виявлення за рахунок використання спеціальних покриттів. Збірник наукових прачь Харківського національного університету Повітряних Сил. 2019. № 2(60). С. 106-112. https://doi.org/10.30748/ zhups.2019.60.14.

12. Сидоренко Р. Г., Грідін В. І., Резніченко А. І., Філіппенков О. В. Оцінка ефективності зниження радіолокаційної помітності об'єктів за рахунок використання розсіюючих та поглинаючих покриттів. Системи озброєння $i$ військова техніка. 2018. № 1(53). С. 189-194. https://doi.org/10.30748/soivt.2018.53.27.

Надійшла до редколегії 03.06.2021 Схвалена до друку 13.07.2021

\section{Відомості про авторів:}

\section{Сидоренко Руслан Григорович}

кандидат технічних наук старший науковий співробітник провідний науковий співробітник

Харківського національного

університету Повітряних Сил ім. І. Кожедуба,

Харків, Україна

https://orcid.org/0000-0002-3097-6747

\section{Information about the authors:}

\author{
Ruslan Sydorenko \\ Candidate of Technical Sciences Senior Research \\ Lead Research \\ of Ivan Kozhedub Kharkiv \\ National Air Force University, \\ Kharkiv, Ukraine \\ https://orcid.org/0000-0002-3097-6747
}


Порохончук Олександр Миколайович старший науковий співробітник Харківського національного університету Повітряних Сил ім. І. Кожедуба, Харків, Україна https://orcid.org/0000-0001-5568-6837
Oleksandr Porokhonchuk

Senior Research

of Ivan Kozhedub Kharkiv

National Air Force University,

Kharkiv, Ukraine

https://orcid.org/0000-0001-5568-6837

\title{
ОЦЕНКА ЭФФЕКТИВНОСТИ СРЕДСТВ СНИЖЕНИЯ ЗАМЕТНОСТИ ОБЪЕКТОВ В ИНФРАКРАСНОМ ДИАПАЗОНЕ ДЛИН ВОЛН
}

\author{
Р.Г. Сидоренко, А.Н. Порохончук
}

Проведена оценка возможностей аппаратуры инфракрасной (тепловизионной) разведки установленной на летательных аппаратах и наземных средствах по обнаружению объектов. Приведены необходимые для расчетов исходные данные относительно аппаратуры, объектов и условий ведения разведки. Получены аналитические выражения для расчета отнотений сигнал/шум изображений исходного и замаскированного объектов и вероятностей их обнаружения. Разработан математический аппарат для оченки эффективности мер снижения заметности в инфракрасном диапазоне длин волн. Полученные результаты могут использоваться при разработке новых средств снижения заметности и оценке эффективности существующих и перспективных средств снижения заметности в инфракрасном диапазоне длин волн аппаратуры тепловизионной разведки.

Ключевые слова: аппаратура тепловизионной разведки, мероприятия маскировки, оценка эффективности, вероятность обнаружения объекта.

\section{EVALUATION OF THE EFFECTIVENESS OF MEANS OF REDUCING OBJECTS THE SIGNATURE IN THE INFRARED RANGE OF WAVELENGTHS}

\author{
R. Sydorenko, O. Porokhonchuk
}

Infrared reconnaissance is now widely used in the armed forces of the world's leading countries to detect and identify ground, air and sea objects, as well as to provide strikes in night and difficult weather conditions. The most widely used are thermal imagers, which are designed to obtain a visual image of the earth's surface and ground objects that have different temperatures or reflectivity. Thermal imaging can be performed at any time of the day, but it is more effective at night when ground objects do not reflect sunlight. The purpose of the article is to develop a method for assessing the effectiveness of the use of means of reducing visibility from the equipment of the imaging reconnaissance. An assessment of the capabilities of infrared (thermal imaging) reconnaissance equipment installed on aircraft and ground means for identifying objects has been carried out. The initial data on equipment, objects and conditions for conducting reconnaissance, necessary for calculations, are given. Analytical expressions are obtained for calculating the signal-to-noise ratio of the images of the original and masked objects and the probabilities of their detection. A mathematical apparatus has been developed for evaluating the effectiveness of measures to reduce the signature in the infrared wavelength range. The results obtained can be used in the development of new means of reducing the signature and assessing the effectiveness of existing and future means of reducing the signature in the infrared range of wavelengths from thermal imaging reconnaissance equipment. The obtained results can provide a calculated assessment of the capabilities of thermal reconnaissance equipment of specific objects of protection in the given conditions, necessary to identify particularly dangerous means of detecting and defeating the enemy, identifying unmasking signs, selection and development of methods and means of counteraction and evaluation of their effectiveness.

Keywords: thermal imaging equipment, camouflage measures, efficiency assessment, probability of object detection. 